\title{
How Help-Seeking Expectations Are Associated with Relational and Physical Victimization among Japanese Adolescents
}

\author{
Haruhisa Mizuno"1, Takuya Yanagida², Yuichi Toda ${ }^{1}$ \\ ${ }^{1}$ Osaka University of Education, Osaka, Japan \\ ${ }^{2}$ University of Vienna, Vienna, Austria \\ Email: hmizuno@cc.osaka-kyoiku.ac.jp
}

How to cite this paper: Mizuno, H., Yanagida, T., \& Toda, Y. (2018). How HelpSeeking Expectations Are Associated with Relational and Physical Victimization among Japanese Adolescents. Psychology, 9, 14121425.

https://doi.org/10.4236/psych.2018.96086

Received: May 2, 2018

Accepted: June 26, 2018

Published: June 29, 2018

Copyright $\odot 2018$ by authors and Scientific Research Publishing Inc. This work is licensed under the Creative Commons Attribution International License (CC BY 4.0).

http://creativecommons.org/licenses/by/4.0/

\begin{abstract}
The purpose of this study was to investigate the relationship between help-seeking expectations and school bullying. Japanese students $(N=532$; $53 \%$ boys, about 12 years-old) were asked to fill out a questionnaire including help-seeking expectations scale and bullying scale. Help-seeking expectations were composed of two kinds of expectations; responsibility expectations and accessibility expectations. Relational victimization on girls was positively associated with help-seeking in both responsibility and accessibility expectations. Higher relational victimization was associated with higher responsibility expectations for girls. For boys, there was a u-shaped relationship between relational victimization and responsibility expectations. There was a reversed $\mathrm{u}$-shaped relationship between relational victimization and accessibility expectations. In sum, much more relationally victimized boys may expect their friends' help (responsibility expectations), but their accessibility expectations may be rather pessimistic.
\end{abstract}

\section{Keywords}

Victimization, Help-Seeking, Gender Role Conflict, Japanese Students

\section{Introduction}

In the last three decades, the research activity concerning school bullying has increased enormously. Smith (2014) describes this research expansion as consisting of four main phases: Origins (1970-1988); establishing research programs (1989-mid 1990s); establishing international research programs (mid 1990s-2004); and cyberbullying (2004-present). In accordance with those phases, intervention programs were developed to reduce school bullying, appearing first in the Ori- 
gins phase, and now the interventional efforts are ongoing in cyberbullying phase.

School bullying is a world-wide problem (Smith et al., 1999). Terms similar to bullying are used to describe the problem with different nuances and approaches to tackle them in each country (Smith et al. 2002). However, the basic nature of the problem includes "systematic abuse of power" (Smith \& Sharp, 1994: p. 2), "relationship problems" (Pepler, 2006) or "repetitive aggression in relationships" (Toda, Strohmeier, \& Spiel, 2008; Toda, 2011).

In Japan, bullying has been one of the serious problems in Japanese schools since mid-1980, occasionally evoking a media focus on suicide cases (Toda, 2016). But it took rather long in Japan until bullying prevention law was enacted (Japanese Ministry of Education, 2013). However, following and learning from Western intervention programs, such as Social and Emotional Learning, social skills training and so on, some pioneer schools have introduced and practiced bullying prevention programs (Koshi, 2013). In addition, school counsellors have been struggling to support victims of bullying and supervising teachers to handle serious cases since 1990's (Yagi, 2008). In order to prevent victimization from bullying effectively, it is important to intervene not only at the school level and classroom level but also at the individual level (Smith, Ananiaduou, \& Cowie, 2003). That is why coping strategies for victims have been developed (e.g., Kochenderfer-Ladd \& Skinner, 2002; Kristensen \& Smith, 2003). These coping strategies were compared between Eastern and Western countries (e.g., Kanetsuna \& Smith, 2002). However, the coping strategies pupils use against bullying have been relatively unexamined in considering bullying prevention.

There are many strategies that pupils use against bullying in Japan but one strategy would be telling others about acts of bullying and seeking help from an appropriate person (Smith \& Shu, 2000). Tenenbaum, Varjas, Meyers, and Parris (2011) interviewed 102 pupils and found that seeking social support were the most commonly reported problem-focused coping strategies used by victims of bullying.

In school settings, friends and teachers are the most common helping resources (Mizuno \& Ishikuma, 2004). Talking about bullying with teachers is an effective help-seeking strategy (Smith \& Shu, 2000). Eliot, Cornell, Gregory, and Fan (2010) reported that pupils who perceived their teachers to be supportive were more likely to endorse positive attitudes toward seeking help. This tendency has been confirmed in Japanese junior high school pupils (Yamanaka \& Hiraishi, 2015). But Boulton (2005) pointed out that almost one in 10 pupils said that they would "definitely not" seek help for bullying from their teachers. Dowling and Carey (2013) reported that teachers are considered to be one of the most difficult sources to talk to about being bullied, and were unlikely to make the victims feel better. Some pupils feel that telling a teacher will even result in worse situations of bullying (Fekkes, Pijpers, \& Verloove-Vanhorick, 2005).

This finding is also applicable to Japanese pupils. Japanese children are more likely to seek help from their friends, rather than teachers or counsellors (Yamaguchi, Mizuno, \& Ishikuma, 2004). Therefore, the establishment of a 
peer-support system appears to be one method for dealing with problems of bullying. Victims of bullying value genuineness and empathic understanding, which is typical of the type of support that close friends offer (Boulton, 2005).

Studies in Western societies show that it is not difficult to seek help from friends (Oliver \& Candappa, 2007). In Japanese pupils, Nagai (2009) points out that children who report severe peer victimization are less likely to seek help from their friends. So in this Japanese sample, the victims of bullying are less likely to seek help even from their friends. As Nakai (1997) explains, the victims of bullying become isolated and are forced to learn helplessness through violence. Help-seeking behaviors show individual differences, due to gender, challenge appraisals, emotions and so on (Hunter, Boyle, \& Warden, 2004). Especially, gender is one of the strongest predictors of help seeking (Glover, Gough, Johnson, \& Cartwright, 2000; Hunter \& Boyle, 2002).

In Japan, research concerning help seeking behaviors in counseling filed stared in 1999 (Mizuno \& Ishikuma, 1999) and the scale of help seeking behaviors is developed by Tamura and Ishikuma (2001). This scale was assessing two dimensions of help seeking expectations. One is positive side of help seeking concerning how helper is responsible for seeking help. And the other side of help seeking is fear and concerns of accessibility of help seeking.

If we can find strong predictors of help-seeking behaviors, then we can develop intervention programs for victims of bullying. Mizuno and Ishikuma (1999) reviewed the literature and identified four predictive variables: 1) demographic variables, 2) network variables, 3) personality variables, and 4) victim symptoms or the seriousness of the problems. But Nagai and Honda (2010) points out that there were no strong predictive variables in their review of studies regarding help-seeking among adolescents in Japan. Mizuno, Ishikuma, and Tamura (2006) points out that the amount of social support and less concern about responsiveness will enhance help-seeking preferences for social and emotional problems from friends. Nagai and Arai (2007) explained that a positive benefit of consulting will enhance help-seeking behaviors from friends for social and psychological problems. We need to know more about why victims seek help or do not seek help when they experience bullying. In this study, we will examine the relationship between victimization and help-seeking expectations from their friends. The main goal of the present study is to investigate relationship between help-seeking expectations and school bullying in Japan.

We focused on school bullying and help-seeking expectations, and hypothesized a linear/non-linear relationship between those constructs. Moreover, we hypothesize that this relationship differs between girls and boys, controlling for age. Because age and gender are the two main factors that affects help seeking behaviors (Mizuno \& Ishikuma, 1999).

\section{Method}

\subsection{Procedure}

We recruited Japanese adolescents from 16 classes of one elementary and one 
junior high school situated in a Japanese city in 2008. In Japan, elementary school comprises grades 1 to 6 and junior high school comprises grades 7 to 9 . Consistent with standard ethical procedures in Japan then, the school principals and teachers approved the study before data collection. The anonymous survey was conducted by homeroom teachers, after the approval of school principals in place of parental consent. Students were told they could leave the study at any time and received post-survey lecture on coping bullying.

\subsection{Participants}

A total of 532 Japanese pupils ( $53 \%$ boys), mean age $12.33(S D=1.78$ ) years, participated in this study. Altogether, 29 records (5.5\%) were incomplete. The percentage of missing values across the 19 variables used in the present study varied between 0.0 and $1.7 \%$. Multiple imputation under the missing at random (MAR) assumption was used to deal with missing data (Rubin, 1987). Incomplete variables were imputed under fully conditional specification (van Buuren, Brand, Groothuis-Oudshoorn, \& Rubin, 2006) including not only variables used in the present study but several potential auxiliary variables (Collins, Schafer, \& Kam, 2001). A total of 20 imputed data sets were extracted during the imputation process. Calculations were done in $\mathrm{R}$ ( $\mathrm{R}$ Core Team, 2014) using the mice package (Van Buuren \& Groothuis-Oudshoorn, 2011).

\subsection{Measures}

1) Help-seeking expectations scale. Help-seeking expectations were measured with items adapted from a scale developed by Tamura and Ishikuma (2001). Four items measured responsibility expectations, e.g., "My friends would understand my emotional feelings when I tell my problems" and three items measured accessibility expectations, e.g., "I feel ashamed in consulting with my friends". All items were presented using a five point Likert-Scale: 1 (strongly agree), 2 (somewhat agree), 3 (neutral), 4 (somewhat disagree), and 5 (strongly disagree). The Cronbach's a coefficient for responsibility expectations was $a$ $=.78$ ( $\alpha=.76$ for girls and $\alpha=.78$ for boys) and for accessibility expectations $\alpha$ $=.58$ ( $\alpha=.57$ for girls and $\alpha=.60$ for boys). Items for accessibility expectations were reversed to enhance interpretability. Thus, high values indicate high accessibility expectations.

2) Relational and overt victimization. Relational and overt victimization were measured with items adapted from the peer nomination measure originally developed by Crick and Grotpeter (1995). Seven items measured relational victimization, e.g., "How often during the last six months have you been excluded from play or another activity by one or more classmates?" and three items measured overt victimization, e.g., "How often have you been hit by one or more classmates during the last two months?" Answers to all questions were given on a five-point response scale: 0 (not at all), 1 (once or twice), 2 (two or three times a month), 3 (once a week), and 4 (nearly every day). The Cronbach's a coeffi- 
cient for relational victimization was $\alpha=.86(\alpha=.83$ for girls and $\alpha=.88$ for boys) and for overt victimization $\alpha=.82$ ( $\alpha=.74$ for girls and $\alpha=.82$ boys).

The items for all the scales used in the present study are shown in Appendix A.

\subsection{Measurement Model}

Confirmatory factor analysis (CFA) using Mplus 7.11 was conducted to investigate the measurement model for help-seeking expectations and relational and overt victimization in the whole sample and for girls and boys assuming strong measurement invariance. For help-seeking expectations, the two-factor model (responsibility expectations and accessibility expectations) with continuous indicators yielded an acceptable model fit for the whole sample $\left(\chi^{2}(13)=46.168, p\right.$ $<.001, \mathrm{CFI}=.936, \mathrm{RMSEA}=.069)$ and across girls and boys $\left(\chi^{2}(36)=84.734, p\right.$ $<.001$, CFI $=.905$, RMSEA $=.071)$. The path diagram of the measurement model is depicted in Figure 1.

For victimization, a two-factor model (overt and relational victimization) with ordered-categorical indicators yielded a good model fit for the whole sample $\left(\chi^{2}\right.$ $(34)=108.153, p<.001$, CFI $=.976$, RMSEA $=.064)$ and across girls and boys $\left(\chi^{2}(99)=169.081, p<.001, \mathrm{CFI}=.979, \mathrm{RMSEA}=.052\right)$.

Factor scores based on the measurement models assuming strong measurement invariance were extracted and subsequently used in the main analysis of the present study.

\subsection{Analytic Strategy}

In order to test the main hypotheses of the study, we conducted regression analyses separately for girls and boys to predict responsibility expectations and accessibility expectations controlling for age. A linear and a quadratic effect of overt and relational victimization was included in the model to account for non-linear relationships between help-seeking expectations and victimization.

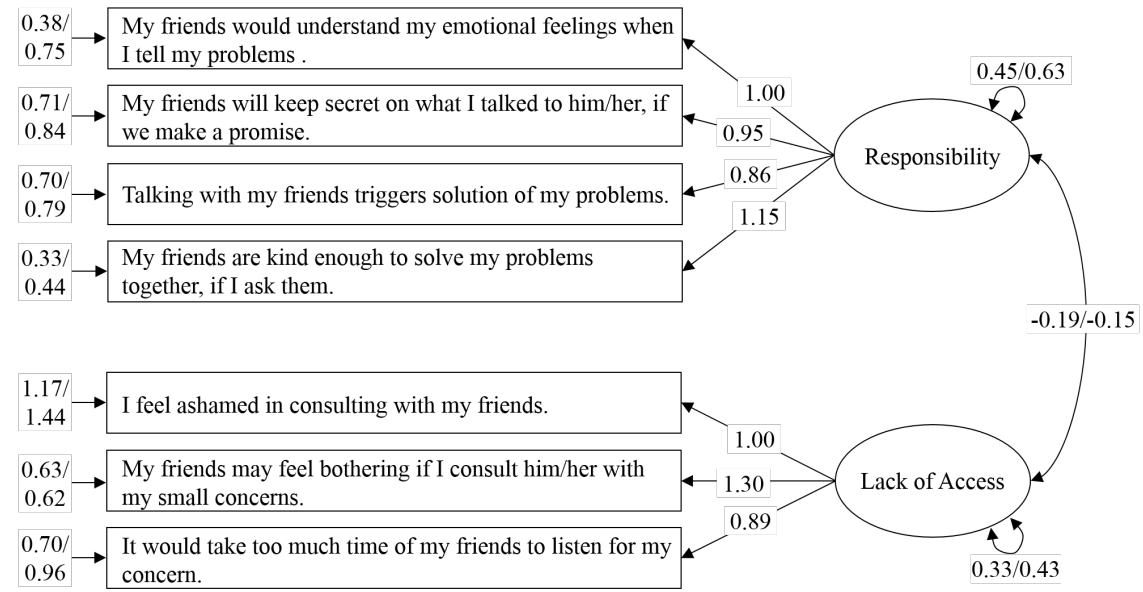

Figure 1. Measurement model of help-seeking expectations: Unstandardized parameter estimates for girls and boys. 
The predictors for overt and relational victimization were centered and subsequently squared to compute the quadratic terms.

\section{Results}

\subsection{Descriptive Statistics}

Means, standard deviations and zero-order correlations of all study variables are presented separately for boys and girls in Table 1 .

\subsection{Relationship between Help-Seeking Expectations and School Bullying}

The results of the regression analyses for girls and boys for the criterion variables responsibility expectations and accessibility expectations are displayed in Table 2.

For responsibility expectations, the regression model was statistically significant for both girls $(F(5,249)=2.465, p<.05)$ and boys $(F(5,281)=7.428, p$ $<.001)$. Thus, the model is useful for predicting responsibility expectations explaining $5.1 \%$ of the variance for girls and $11.8 \%$ of the variance for boys. The linear term of relational victimization was statistically significant for predicting responsibility expectations $(b=.297, p<.05)$ for girls, controlling for all other predictors in the model. Higher relational victimization corresponded to higher responsibility expectations for girls. However, the quadratic term of relational victimization was statistically significant for predicting responsibility expectations $(b=.307, p<.05)$ for boys. This indicates a $\mathrm{u}$-shaped relationship between relational victimization and responsibility expectations. More specifically, there is a negative relationship between relational victimization and responsibility expectations below the mean of relational victimization, but an increasing positive relationship above the mean of relational victimization. See Figure 2 (Panel A)

Table 1. Means, standard deviations, and zero-order correlations among study variables for girls and boys.

\begin{tabular}{cccccc}
\hline Variable & 1 & 2 & 3 & 4 & 5 \\
1 Age & - & -.164 & -.099 & -.021 & .026 \\
2 Relational victimization & -.146 & - & .646 & .243 & .211 \\
3 Overt victimization & -.420 & .477 & - & .248 & .190 \\
4 Responsibility expectations & .046 & -.196 & -.018 & - & .420 \\
5 Accessibility expectations & -.004 & .270 & .060 & .529 & - \\
$\mathrm{M}_{\text {girls }}$ & 12.34 & .13 & -.07 & 2.14 & 3.32 \\
$\mathrm{SD}_{\text {girls }}$ & 1.77 & .50 & .48 & 0.60 & .51 \\
$\mathrm{M}_{\text {boys }}$ & 12.32 & .10 & .29 & 2.45 & 3.25 \\
$\mathrm{SD}_{\text {boys }}$ & 1.79 & .51 & .74 & .71 & .55 \\
\hline
\end{tabular}

Note. Correlations for girls are shown in the lower triangle, correlations for boys are shown in the upper triangle; statistically significant correlations at $\alpha=.05$ are shown in bold. 
Table 2. Multiple regression: Results for girls and boys for responsibility expectations and accessibility expectations.

\begin{tabular}{|c|c|c|c|c|c|c|c|c|c|c|c|c|}
\hline & \multicolumn{6}{|c|}{ Responsibility Expectations } & \multicolumn{6}{|c|}{ Accessibility Expectations } \\
\hline & \multirow{2}{*}{$\begin{array}{l}\text { Unstandardized } \\
\text { Estimate }\end{array}$} & \multirow{2}{*}{ SE } & \multirow{2}{*}{$p$-value } & \multicolumn{2}{|c|}{$95 \% \mathrm{CI}$} & \multirow{2}{*}{$\mathrm{R}^{2}$} & \multirow{2}{*}{$\begin{array}{l}\text { Unstandardized } \\
\text { Estimate }\end{array}$} & \multirow{2}{*}{ SE } & \multirow{2}{*}{$p$-value } & \multicolumn{2}{|c|}{$95 \% \mathrm{CI}$} & \multirow{2}{*}{$R^{2}$} \\
\hline & & & & lower & upper & & & & & lower & upper & \\
\hline Girls & & & & & & .051 & & & & & & .080 \\
\hline intercept & 2.153 & .072 & $<.05$ & 2.011 & 2.294 & & 3.346 & .060 & $<.05$ & 3.229 & 3.463 & \\
\hline relational linear & .297 & .127 & $<.05$ & .049 & .545 & & .281 & .104 & $<.05$ & -.485 & -.076 & \\
\hline relational quadratic & -.045 & .164 & .786 & -.367 & .278 & & .062 & .136 & 648 & -.328 & .204 & \\
\hline overt linear & -.141 & .114 & .216 & -.363 & .082 & & -.075 & .094 & .426 & -.109 & .258 & \\
\hline overt quadratic & -.108 & .189 & .569 & -.478 & .263 & & -.033 & .156 & .833 & -.273 & .339 & \\
\hline age & -.021 & .024 & .380 & -.068 & .026 & & .003 & .020 & .866 & -.042 & .036 & \\
\hline Boys & & & & & & .118 & & & & & & .086 \\
\hline intercept & 2.291 & .056 & $<.05$ & 2.181 & 2.401 & & 3.183 & .045 & $<.05$ & 3.096 & 3.271 & \\
\hline relational linear & -.074 & .150 & .624 & -.368 & .221 & & .421 & .119 & $<.05$ & -.654 & -.187 & \\
\hline relational quadratic & .307 & .120 & $<.05$ & .072 & .542 & & -.277 & .096 & $<.05$ & .090 & .464 & \\
\hline overt linear & .138 & .109 & .204 & -.075 & .352 & & -.007 & .087 & .932 & -.163 & .178 & \\
\hline overt quadratic & .088 & .086 & .306 & -.080 & .255 & & .029 & .068 & .666 & -.162 & .104 & \\
\hline age & -.007 & .023 & .759 & -.052 & .038 & & .025 & .018 & .177 & -.060 & .011 & \\
\hline
\end{tabular}

Note. $\mathrm{SE}=$ standard error; $95 \% \mathrm{CI}=95 \%$ confidence interval; statistically significant results $\alpha=.05$ are shown in bold; relational and overt victimization and age are centered.

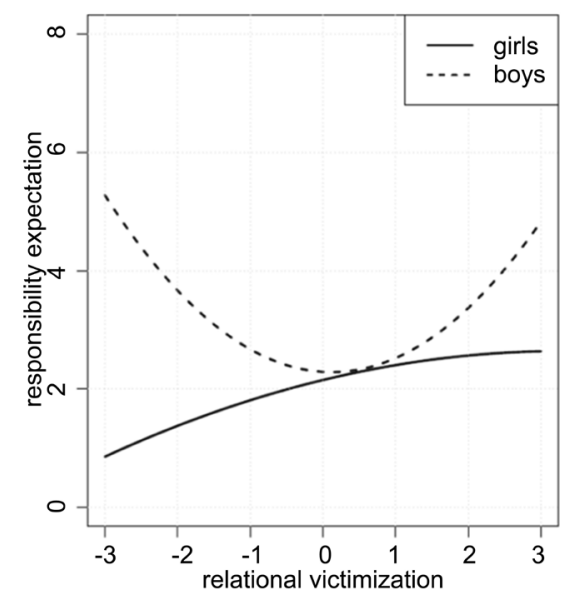

(A)

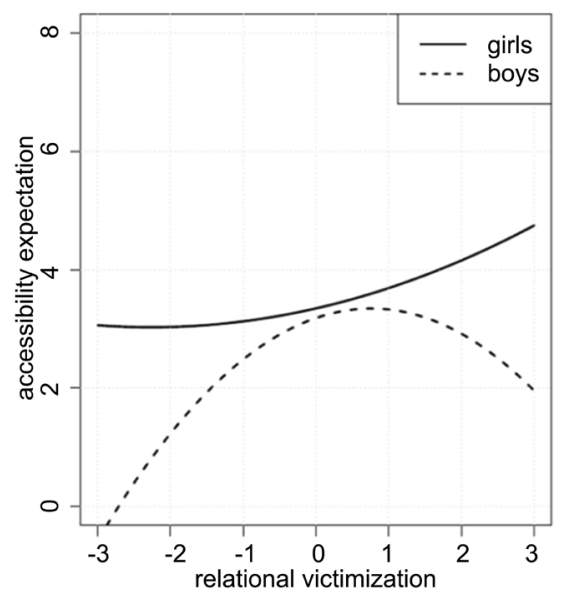

(B)

Figure 2. Model implied relationships between relational victimization and criterion variables; responsibility expectations in Panel A and accessibility expectations in Panel B. Note: Overt victimization and age are statistically held constant.

for the relationship between relational victimization and responsibility expectations for girls and boys separately. All other predictors in the model were not statistically significant.

For accessibility expectations, the regression model was statistically significant 
for both girls $(F(5,249)=4.132, p<.01)$ and boys $(F(5,281)=4.936, p<.001)$. Thus, the model is useful for predicting responsibility expectations, explaining $8.0 \%$ of the variance for girls and $8.6 \%$ of the variance for boys. The linear term of relational victimization was statistically significant for predicting responsibility expectations for girls $(b=.281, p<.05)$ and for boys $(b=.421, p<.05)$, controlling for all other predictors in the model. In addition, the quadratic term of relational victimization was statistically significant for predicting responsibility expectations $(b=-0.277, p<.05)$ for boys. Thus, there is a reversed $\mathrm{u}$-shaped relationship between relational victimization and accessibility expectations. More specifically, there is a positive relationship between relational victimization and responsibility expectations below the mean for relational victimization, but an increasing negative relationship above the mean for relational victimization. See Figure 2 (Panel B) for the relationship between relational victimization and accessibility expectations for girls and boys separately. All other predictors in the model were not statistically significant.

\section{Discussion}

The main goal of the present study was to investigate the relationship between help-seeking expectations and relational and overt victimization. First, by conducting Structural Equation Modeling, we found that help-seeking expectations are composed of two kinds of expectations: responsibility expectations and accessibility expectations.

We hypothesized that experiencing school bullying would predict help-seeking expectations. The most important finding from the results of the present study is that the relationship between victimization and help-seeking expectations is complex, especially among boys. Regarding the relationship between relational victimization and responsibility expectations, the results show that relational victimization for girls is positively associated with help-seeking expectation. The linear term of relational victimization was statistically significant for predicting responsibility expectations for girls, controlling for all other predictors in the model. Higher relational victimization corresponds to higher responsibility expectation for girls.

However, the results suggest some complexity for boys. The quadratic term of relational victimization was significant for predicting responsibility expectations. More specifically, there was a negative relationship between relational victimization and responsibility expectations below the mean for relational victimization, but an increasingly positive relationship above the mean for relational victimization. Thus, boys who experience victimization have higher scores for responsibility expectations, which indicates a positive attitude toward help-seeking.

Regarding accessibility expectations, the linear term of relational victimization was statistically significant for predicting accessibility expectations for both girls and boys. In addition, the quadratic term of relational victimization was statistically significant for predicting responsibility expectations for boys. Thus, there is 
a reversed $\mathrm{u}$-shaped relationship between relational victimization and accessibility expectations. More specifically, there is a positive relationship between relational victimization and accessibility expectations below the mean for relational victimization, but an increasingly negative relationship above the mean for relational victimization.

Regarding responsibility expectations, boys who experience severe relational victimization may seek help from friends. However, for accessibility expectations, boys who experience severe relational victimization may not seek help from friends. Some research studies are in conflict with the results of our present study (Mouttapa, Valente, Gallaher, Rohrback, \& Unger, 2004; Wilson, 2010). Nevertheless, our results support Nagai (2009)'s study of Japanese elementary school students. Furthermore, the results of the present study are a little more complicated. Much more victimized boys may expect their friends' help (responsibility expectations), but their accessibility expectations may be rather pessimistic.

One possible explanation for this finding is gender role conflict theory, which suggests that because boys have a masculine gender identity they may hesitate to seek help because seeking help is seen as feminine behavior (Good, Dell, \& Mintz, 1989). Not surprisingly, Japanese male pupils score higher on a masculinity scale than female pupils (Sugihara \& Katsurada, 2000). Therefore, in our study, boys might have had a stronger inclination not to seek help because of their masculine identity, which might have reduced accessibility expectations for those who experienced relational victimization. One key factor that interferes with help-seeking by those who have a strong masculine identity is emotional openness. Boys with a strong masculine identity tend not to be open about their emotions. This may explain the findings for the boys in the present study. Boys are reluctant to be open about their emotional experiences with friends. That is why boys who experience relational victimization need to be open about their emotions when they seek help from friends (Good, Dell, \& Mintz, 1989).

Another possible explanation is that boys who experience severe relational victimization may have some kind of difficulty in seeking help. O'Neil (2013) reviewed research concerning gender role conflicts and asserted that men who had a high score on a gender role conflict scale reported greater difficulty coping with problems. Boys, who had been experiencing relational victimization, may experience gender role conflict, which might explain their hesitancy to ask friends for help. But further research is needed to explore why boys showed these complex results.

The implications for intervention are that it may be necessary to take two different approaches to deal with bullying for boys and girls. A suggested intervention for boys to increase help-seeking expectations about teachers and counselors should have more focus on bullying. One possible solution for victimized boys should take into account the boys' help-seeking styles. When bullying is occurring, the intervention should consist of improving the classroom climate, 
such as the creation of a harmonious classroom climate. This harmonious classroom climate may influence boys to seek help. Promoting the attitude that bullying is unacceptable may lead to more boys seeking help (Williams \& Cornell, 2006). It is generally essential for schools to create an environment that discourages bullying, and for teachers to provide support for children. However, support for boys in particular should include careful observation to identify bullying victimization since our findings suggest that boys are less likely to seek help from peers than girls. The approach to bullying/victimization should consider disclosing the presence of bullying cases at school, and thereby guiding boys to express their negative emotion about victimization. One of the potentially effective solutions would be to provide boys with opportunities to reflect on their expression of feelings in a safe environment. Incorporating Social-Emotional Learning (SEL) into the work of teachers and counselors might serve as an effective solution helping boys to reflect their emotional feelings and try to express it in safer circumstances. Though, further research is needed to identify effective ways to support boys who are experiencing victimization from bullying.

As for limitations, this study derived from a questionnaire research administered at only one time point. As a next step, a longitudinal study should be considered. Second, as the pupils are asked about how they seek help from their friends, the answers may reflect their social networks, which should be considered in the further research. Finally, this study analyze data from Japanese context. However, the questionnaire did not include scales which reflect Asian values or collectivism (cf. Triandis \& Gelfland, 1998). The results, especially about boys, may have been influenced by Asian values that discourage disclosing emotional feelings (Lim, 2016). Thus, research into help seeking related to bullying of Japanese pupils should be conducted in the context of Asian value and culture in the future.

\section{References}

Boulton, M. J. (2005). School Peer Counselling for Bullying Services as a Source of Social Support: An Interview Study with Secondary School Pupils. British Journal of Guidance and Counselling, 33, 485-494. https://doi.org/10.1080/03069880500327546

Collins, L. M., Schafer, J. L., \& Kam, C.M. (2001). A Comparison of Inclusive and Restrictive Strategies in Missing Data Procedures. Psychological Methods, 6, 330-351. https://doi.org/10.1037/1082-989X.6.4.330

Crick, N. R., \& Grotpeter, J. K. (1995). Relational Aggression, Gender, and SocialPsychological Adjustment. Child Development, 66, 710-722. https://doi.org/10.2307/1131945

Dowling, M. J., \& Carey, T. A. (2013). Victims of Bullying: Whom They Seek Help from and Why: An Australian Sample. Psychology in the Schools, 50, 798-808. https://doi.org/10.1002/pits.21709

Eliot, M., Cornell, D., Gregory, A., \& Fan, X. (2010). Supportive School Climate and Student Willingness to Seek Help for Bullying and Threats of Violence. Journal of School Psychology, 48, 533-553. https://doi.org/10.1016/j.jsp.2010.07.001

Fekkes, M., Pijpers, F. I. M., \& Verloove-Vanhorick, S. P. (2005). Bullying: Who Does 
What, When and Where? Involvement of Children, Teachers and Parents in Bullying Behavior. Health Education Research: Theory \& Practice, 20, 81-91.

https://doi.org/10.1093/her/cyg100

Glover, D., Gough, G., Johnson, M., \& Cartwright, N. (2000). Bullying in 25 Secondary Schools: Incidence, Impact and Intervention. Educational Research, 42, 141-156. https://doi.org/10.1080/001318800363782

Good, G. E., Dell, D. M., \& Mintz, L. B. (1989). Male Role and Gender Role Conflict: Relations to Help-Seeking in Men. Journal of Counseling Psychology, 36, 295-300. https://doi.org/10.1037/0022-0167.36.3.295

Hunter, S. C., \& Boyle, J. M. E. (2002). Perceptions of Control in the Victims of School Bullying: The Importance of Early Intervention. Educational Research, 44, 323-336. https://doi.org/10.1080/0013188022000031614

Hunter, S. C., Boyle, J. M. E., \& Warden, D. (2004). Help Seeking amongst Child and Adolescent Victims of Peer-Aggression and Bullying: The Influence of School-Stage, Gender, Victimization, Appraisal, and Emotion. British Journal of Educational Psychology, 74, 375-390. https://doi.org/10.1348/0007099041552378

Japanese Ministry of Education (2013). Ijimebōshitaisakusuishinhō no kofu ni tsuite ( tsüchì) [On the Proclamation of Bullying Prevention Law]. http://www.mext.go.jp/a_menu/shotou/seitoshidou/1337219.htm

Kanetsuna, T., \& Smith, P. K. (2002). Pupil Insights into Bullying, and Coping with Bullying: A Bi-National Study in Japan and England. Journal of School Violence, 1, 5-29. https://doi.org/10.1300/J202v01n03_02

Kochenderfer-Ladd, B., \& Skinner, K. (2002). Children's Coping Strategies: Moderators of the Effects of Peer Victimization. Developmental Psychology, 38, 267-278.

https://doi.org/10.1037/0012-1649.38.2.267

Koshi, R. (2013). Nihon no GakkoniokeruYoboukyoiku no genjo to Kadai [The Current Statusand Challenges Facing Prevention Programs against Bullying in Japanese Schools]. In K. Yamasaki, Y. Toda, \& Y. Watanabe (Eds.), Sekai no GakkouYobouKyouiku: Sinshin no Kenko to Tekiowo Mamoru Kakkoku no Trikumi [Prevention Education at Schools in the World: The Actions of Each Country for Children's Health and Adjustment] (pp. 263-280). Tokyo: Kaneko-Shobo.

Kristensen, S. M., \& Smith, P. (2003). The Use of Coping Strategies by Danish Children Classed as Bullies, Victims, Bully/Victims, and Not Involved, in Response to Different (Hypothetical) Types of Bullying. Scandinavian Journal of Psychology, 44, 479-488. https://doi.org/10.1046/j.1467-9450.2003.00369.x

Lim, N. (2016). Asian Values that Discourage Disclosing Emotional Feelings. Integrative Medicine Research, 5, 105-109. https://doi.org/10.1016/j.imr.2016.03.004

Mizuno, H., \& Ishikuma, T. (1999). Help-Seeking Preferences and Help-Seeking Behaviors: An Overview of Studies. Japanese Journal of Educational Psychology, 47, 530-539. https://doi.org/10.5926/jjep1953.47.4_530

Mizuno, H., \& Ishikuma, T. (2004). An Overview of Studies on Social Support for Children: Some Implications for Research and Practice in School Psychology in Japan. Japanese Journal of Counseling Science, 37, 280-290.

Mizuno, H., Ishikuma, T., \& Tamura, S. (2006). Help Seeking Preferences of Junior High School Students in Japan. Japanese Journal of Counseling Science, 39, 17-27.

Mouttapa, M., Valente, T., Gallaher, P., Rohrback, L. A., \& Unger, J. B. (2004). Social Network Predictors of Bullying and Victimization. Adolescence, 39, 315-335.

Nagai, S. (2009). Help-Seeking Intentions of Elementary School Students: Relationship 
with Satisfaction with School Life, Experience of Concerns and Depression. Japanese Journal of School Psychology, 9, 17-24.

Nagai, S., \& Arai, K. (2007). Expectation of Cost and Benefit, and Consulting with Peers: Junior High School Students. Japanese Journal of Educational Psychology, 55, 197-207. https://doi.org/10.5926/jjep1953.55.2_197

Nagai, S., \& Honda, M. (2010). An Overview of Studies on Help-Seeking among Adolescents. Bulletin of Tsukuba Developmental and Clinical Psychology, 21, 17-21.

Nakai, H. (1997). Ariadonekara no Ito [Ariadne's Thread]. Tokyo: Misuzu-Shobo.

O’Neil, J. M. (2013). Gender Role Conflict Research 30 Years Later: An Evidence-Based Diagnostic Schema to Assess Boys and Men in Counseling. Journal of Counseling \& Development, 91, 490-498. https://doi.org/10.1002/j.1556-6676.2013.00122.x

Oliver C., \& Candappa, M. (2007). Bullying and the Politics of “Telling”. Oxford Review of Education, 33, 71-86. https://doi.org/10.1080/03054980601094594

Pepler, D. J. (2006). Bullying Interventions: A Binocular Perspective. Journal of the Canadian Academy of Child and Adolescent Psychiatry, 15, 16-20.

R Core Team (2014). R: A Language and Environment for Statistical Computing [Computer Software]. http://www.R-project.org/

Rubin, D. B. (1987). Multiple Imputation for Nonresponse in Surveys. New York, NY: Wiley \& Sons. https://doi.org/10.1002/9780470316696

Smith, P. K. (2014). Understanding School Bullying: Its Nature and Prevention Strategies. London: Sage Publications. https://doi.org/10.4135/9781473906853

Smith, P. K., \& Sharp, S. (1994). School Bullying: Insights and Perspectives. London: Routledge. https://doi.org/10.4324/9780203425497

Smith, P. K., \& Shu, S. (2000). What Good Schools Can Do about Bullying: Findings from a Survey in English Schools after a Decade of Research and Action. Childhood, 7, 193-212. https://doi.org/10.1177/0907568200007002005

Smith, P. K., Ananiadou, K., \& Cowie, H. (2003). Interventions to Reduce School Bullying. The Canadian Journal of Psychiatry, 48, 591-599.

https://doi.org/10.1177/070674370304800905

Smith, P. K., Morita, Y., Junger-Tas, J., Olweus, D., Catalano, R., \& Slee, P. (1999). The Nature of School Bullying: A Cross-National Perspective. London: Routledge.

Sugihara, Y., \& Katsurada, E. (2000). Gender-Role Personality Traits in Japanese Culture. Psychology of Women Quarterly, 24, 309-318. https://doi.org/10.1111/j.1471-6402.2000.tb00213.x

Tamura, S., \& Ishikuma, T. (2001). Help-Seeking Preferences and Burnout: Junior High School Teachers in Japan. Japanese Journal of Educational Psychology, 49, 438-448. https://doi.org/10.5926/jjep1953.49.4_438

Tenenbaum, L. S., Varjas, K., Meyers, J., \& Parris, L. (2011). Coping Strategies and Perceived Effectiveness in Fourth through Eighth Grade Victims of Bullying. School Psychology International, 32, 263-287. https://doi.org/10.1177/0143034311402309

Toda, Y. (2011). Bullying (ijime) and Its Prevention in Japan: A Relationships Focus. In R. Shute, P. Slee, R. Murray-Harvey, \& K. Dix (Eds.), Mental Health and Wellbeing: Educational Perspectives (pp. 179-189). Adelaide, South Australia: Shannon Research Press.

Toda, Y. (2016). Bullying (ijime) and Related Problems in Japan: History and Research. In P.K. Smith, K.M. Kwak, \& Y. Toda (Eds.), School Bullying in Different Cultures: Eastern and Western Perspectives (pp. 73-92). Cambridge, UK: Cambridge University 
Press. https://doi.org/10.1017/CBO9781139410878.007

Toda, Y., Strohmeier, D., \& Spiel, C. (2008). Hitowooitsumeruijime [Process Model of Bullying]. In T. Katoh, \& H. Taniguchi (Eds.), Taijinkankei no da'akusaido [Darkside of Interpersonal Relationships] (pp. 117-131). Kyoto: Kitaohji-Shobo.

Triandis, H. C., \& Gelfland, M. J. (1998). Converging Measurement of Horizontal and Vertical Individualism and Collectivism. Journal of Personality and Social Psychology, 74, 118-128. https://doi.org/10.1037/0022-3514.74.1.118

van Buuren, S., \& Groothuis-Oudshoorn, K. (2011). Mice: Multivariate Imputation by Chained Equations in R. Journal of Statistical Software, 45, 1-67.

https://doi.org/10.18637/jss.v045.i03

van Buuren, S., Brand, J. P. L., Groothuis-Oudshoorn, C. G. M., \& Rubin, D. B. (2006). Fully Conditional Specification in Multivariate Imputation. Journal of Statistical Computation and Simulation, 76, 1049-1064. https://doi.org/10.1080/10629360600810434

Williams, F., \& Cornell, D. G. (2006). Student Willingness to Seek Help for Threats of Violence in Middle School. Journal of School Violence, 5, 35-49.

https://doi.org/10.1300/J202v05n04_04

Wilson, C. J. (2010). General Psychological Distress Symptoms and Help-Avoidance in Young Australians. Advances in Mental Health, 9, 63-72. https://doi.org/10.5172/jamh.9.1.63

Yagi, D. T. (2008). Current Developments in School Counseling in Japan. Asian Journal of Counselling, 15, 141-155.

Yamaguchi, T., Mizuno, H., \& Ishikuma, T. (2004). Relationship between Perceived Problems and Help-Seeking Preferences in Junior High Students. Japanese Journal of Counseling Science, 34, 241-249.

Yamanaka, D., \& Hiraishi, K. (2015). Seeking Help from Teachers by Victims of Bullying in Middle School: Focusing on Student-Teacher Relationship, Loneliness, and Perceived Seriousness of Bullying. Japanese Journal of School Psychology, 15, 31-42. 


\section{Appendix A}

\section{Responsibility Expectations}

1) My friends would understand my feelings when I tell them my problems.

2) My friends will keep secret what I talked to them about, if we make a promise.

3) Talking with my friends triggers solutions of my problems.

4) My friends are kind enough to solve my problems with me, if I ask them.

\section{Accessibility Expectations}

1) I feel ashamed in consulting with my friends.

2) My friends may feel bothered if I consult them about my small concerns.

3) It would take too much of my friends' time to listen to my concerns.

\section{Relational victimization}

1) During the last 3 months, how often have you been left out on purpose by a young person or a group of young persons when it was time to play or do an activity?

2) During the last 3 months, how often has a young person or a group of young persons who were mad at you got back at you by not letting you be in their group anymore?

3) During the last 3 months, how often has a young person or a group of young persons told lies about you to make other kids not like you anymore?

4) During the last 3 months, how often has a young person or a group of young persons told you they won't like you unless you do what they say?

5) During the last 3 months, how often has a young person or a group of young persons tried to keep others from liking you by saying mean things about you?

6) During the last 3 months, how often has a young person or a group of young persons suddenly stopped talking and stayed silent when you approached them?

7) During the last 3 months, how often has a young person or a group of young persons treated you as if you were not there?

\section{Overt victimization}

1) During the last 3 months, how often have you been hit by a young person or a group of young persons?

2) During the last 3 months, how often have you been pushed or shoved by a young person or a group of young persons?

3) During the last 3 months, how often have you been kicked or have been pulled by the hair by a young person or a group of young persons? 